\title{
Silos y arte urbano se combinan para la inclusión social en el entorno rural
}

Titanes es un proyecto de inclusión social de personas con discapacidad, de promoción del arte urbano y el patrimonio rural, a partir de la recuperación de los antiguos silos de grano mediante su intervención artística. Este proyecto, cuya primera edición se ha llevado a cabo en 2019, es un claro ejemplo de cómo poner a disposición de la sociedad el enorme potencial y talento creativo de 500 personas con discapacidad intelectual, enfermedad mental y TEA (Trastorno del Espectro Autista) de la provincia de Ciudad Real.

Alfonso Gutiérrez Caballero | Laborvalía

Url de la contribución <www.iaph.es/revistaph/index.php/revistaph/article/view/4553>

Impulsado y financiado por la Diputación Provincial de Ciudad Real, y desarrollado con el apoyo de la Asociación Laborvalía, Titanes es una apuesta clara por poner en valor el talento de las personas con discapacidad y revalorizar el entorno rural, mediante la recuperación de los silos, espacios y edificios en desuso, generando un flujo de actividad cultural en las áreas rurales.

Titanes ha conseguido unir el talento de artistas de renombre internacional con artistas con discapacidad. Todos ellos han contribuido a dar color a nuestra provincia dejando un legado que supone el mayor ejemplo de arte inclusivo a nivel internacional y el mayor museo al aire libre del mundo.

En todo este proceso las personas con discapacidad no han estado solas, sino que han contado con la colaboración de quince artistas que forman parte de la historia del arte urbano a nivel mundial, como son Okuda San Miguel, Bicicleta Sem Freio (Brasil), Daniel Muñoz, Demsky J., Equipo Plástico (formado por Eltono, Nano4814, Nuria Mora y Sixe Paredes), Fintan Magee (Australia), Hell'O (Bélgica), Smithe (México), Nychos (Austria), Ricardo Cavolo y Spok Brillor, coordinados por la empresa Ink and Movement.

Los silos de nuestra provincia destacan por su altura $y$ se erigen en referentes en el paisaje rural. Forman parte de nuestro patrimonio, aunque la gran mayoría de ellos están olvidados y en desuso. Desde la entrada de

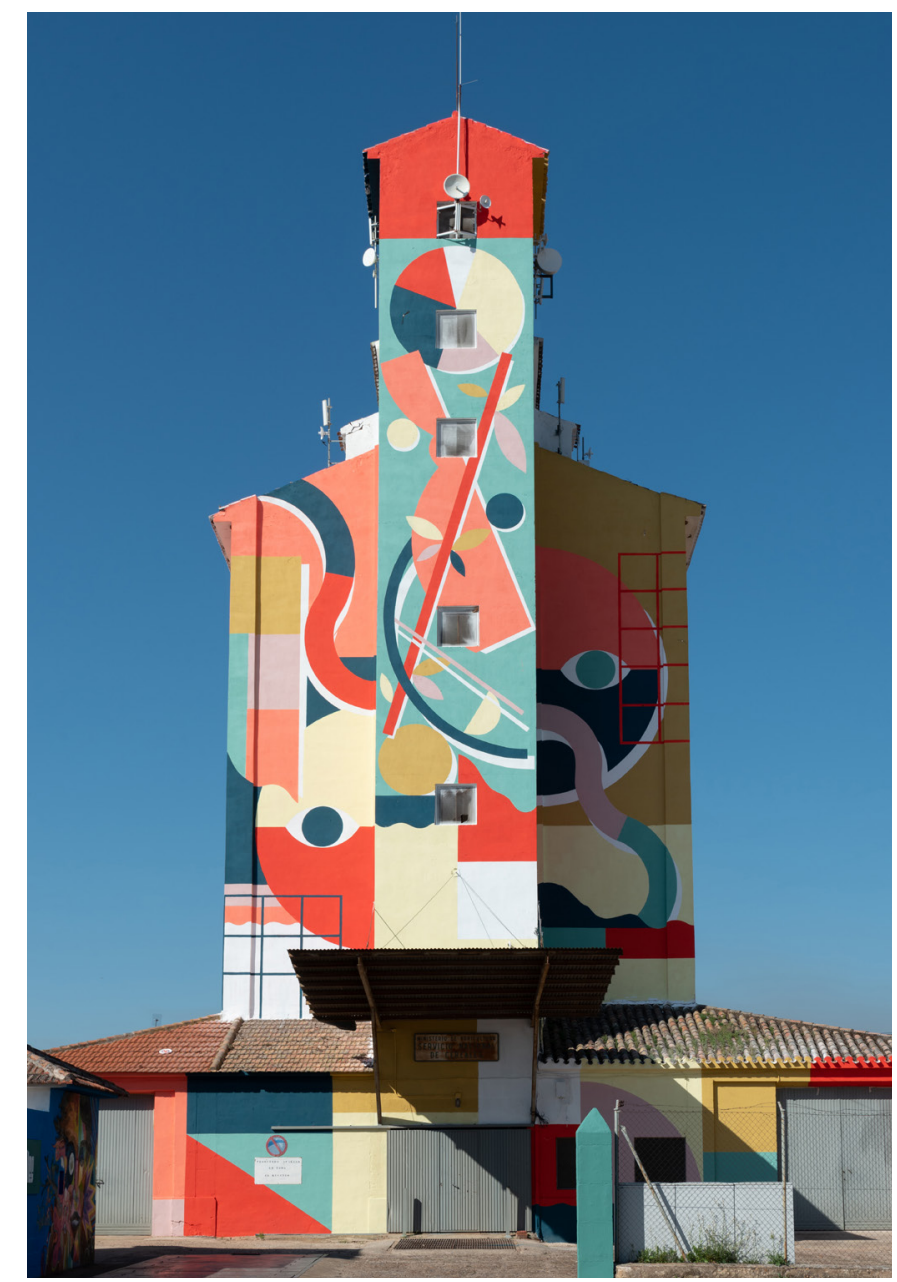

Malagón. Hell’o Collective | fuente Laborvalía, de todas las imágenes que ilustran esta contribución 


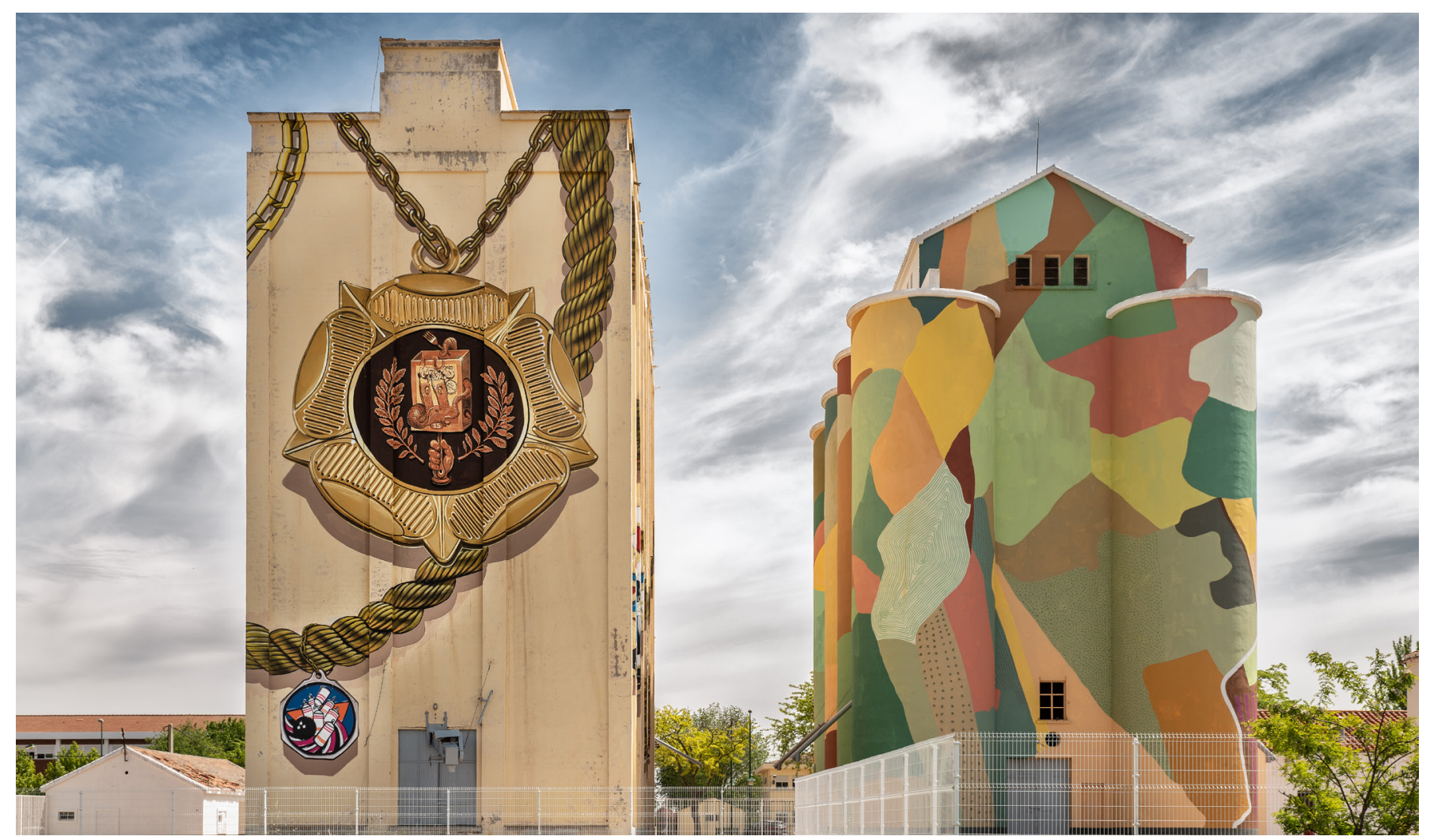

Manzanares. Spook, Daniel Muñoz y Equipo Plástico
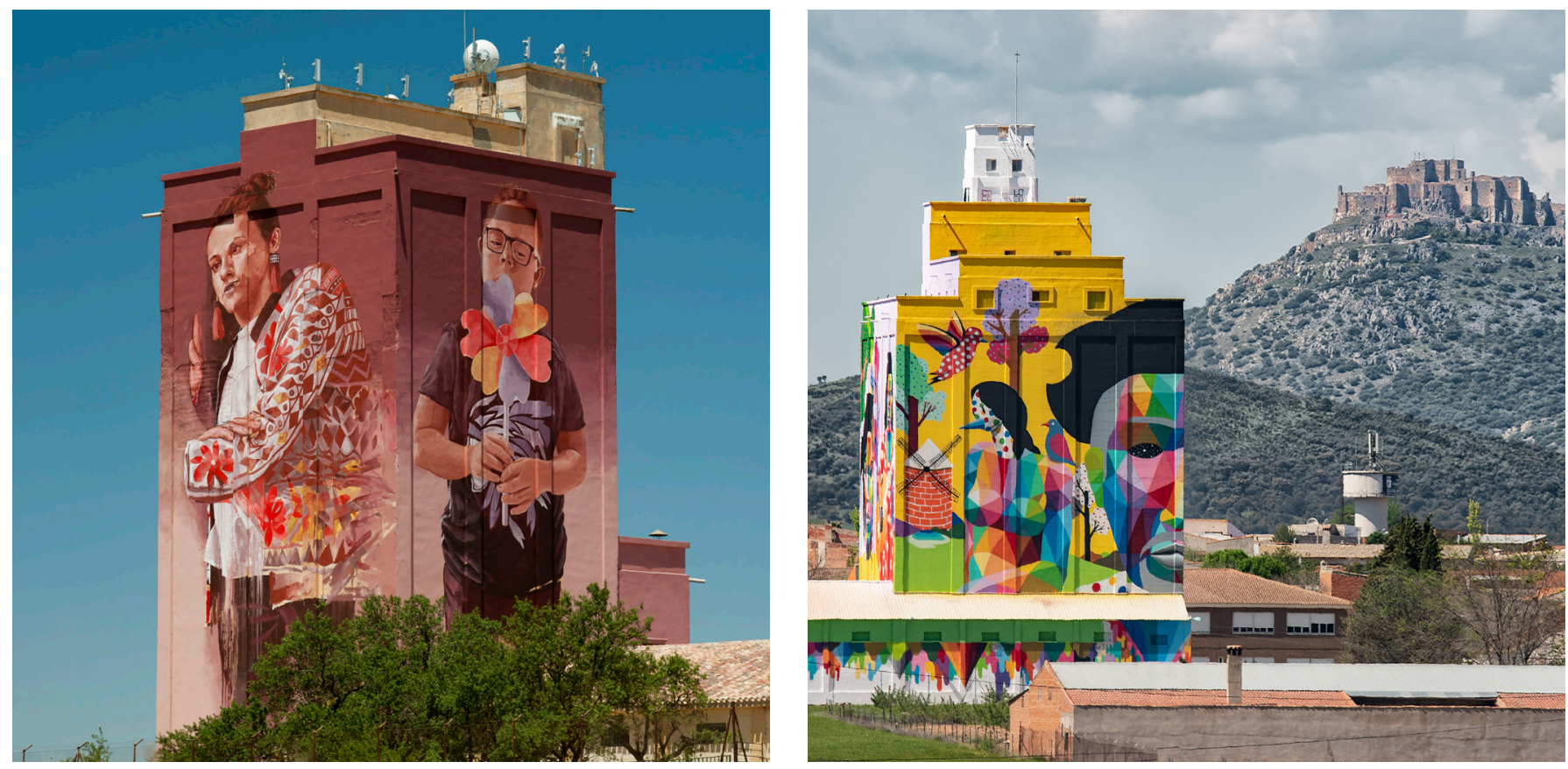

Calzada de Calatrava. Okuda San Miguel 
España en la Comunidad Económica Europea la gran mayoría de los silos pierde su función y quedan relegados a ser almacenes de los ayuntamientos, aunque siguen presidiendo la imagen de los pueblos.

En esta primera edición, durante el año 2019, se han intervenido diez silos, recuperándolos y convirtiéndolos en referentes culturales de la llanura manchega. Los silos se han transformado en los aliados de nuestros molinos de viento, nuestros "Gigantes", referentes de la literatura mundial y que ahora conviven con nuestro Titanes, ejemplo de arte urbano a nivel mundial.

Nuestra intención es cambiar la imagen que la sociedad tiene de las personas con discapacidad, que tradicionalmente han sido receptoras de políticas asistenciales, influyendo en su percepción social, y, a través del arte, trasmitir las ideas de capacidad, talento y creatividad, habilidades puestas además al servicio de la comunidad. Este concepto es todavía más claro en el ámbito rural, y qué mejor que intervenir los edificios que más visibilidad tienen, dándoles un nuevo uso.

La elección de los silos y del arte urbano representaba para el proyecto también una analogía con el desarrollo de la imagen de las personas con discapacidad. El término arte urbano o callejero, traducción de la expresión street art, hace referencia a todo el arte de la calle, frecuentemente fuera de la normalidad e incluso rallando la ilegalidad. Un arte diferente. Estos artistas diferentes, perseguidos por sus "pintadas" hace unos años, son los más aclamados del momento y recorren el mundo aportando color. Las personas con discapacidad tradicionalmente han sido consideradas y tratadas de forma diferente al resto, participando poco en la sociedad y ocupando espacios en entornos que se podrían considerar aislados. Sin embargo, ahora, la sociedad empieza a conocer y reconocer las capacidades y el enorme talento de las personas con discapacidad y cómo desde la diferencia se aportan enormes valores para la construcción de una sociedad mejor.

De ahí que Titanes es un proyecto que aporta valor desde la diferencia; ser diferente no es hándicap, ser diferente es un valor, ser diferente suma. Titanes son enormes personas, enormes artistas, enormes paredes, inmensos valores.

En las intervenciones han participado más de 500 personas con discapacidad, 50 monitores, 16 artistas internacionales, más de 400 niños de colegios de la provincia, institutos, asociaciones locales, artistas locales, etc. Titanes ha conseguido traspasar fronteras y se ha convertido en un referente a nivel mundial. Medios de comunicación de todo el mundo se han hecho eco de la noticia, poniendo en valor el talento de las personas con discapacidad y trasmitiendo una imagen en positivo del colectivo. La apuesta de la Diputación Provincial de Ciudad Real por la inclusión, por el talento y por la revalorización del entorno rural, ha sido la clave del éxito del proyecto Titanes.

Más información:

https://iamtitanes.com

https://www.dipucr.es

\section{Silos intervenidos y artistas participantes}

Calzada de Calatrava: Okuda San Miguel

Corral de Calatrava: Demsky J, Smithe (México)

Herencia: Fintan Magge (Australia)

La Solana: Bicicleta Sem Freio (Brasil)

Malagón: Hell’O (Bélgica)

Manzanares (I): Spok Brillor, Daniel Muñoz

Manzanares (II): Equipo Plástico (Eltono, Nano4814, Nuria Mora y Sixe Paredes)

Porzuna: Nychos (Austria)

Villanueva de los Infantes: Okuda San Miguel

Campo de Criptana: Ricardo Cavolo 